\title{
Pablo Macera, una vida al servicio de la renovación teórica y metodológica de las ciencias sociales ${ }^{1}$
}

Se me pide un testimonio acerca de mi experiencia de formación profesional con Pablo Macera, y una opinión sobre su obra y metodología de trabajo intelectual. Intentaré resumir lo solicitado, primero como alumna del maestro, y luego como investigadora con más de veinte años de aprendizaje continuo en el Seminario de Historia Rural Andina - SHRA, centro de investigación sanmarquino fundado en marzo de 1966 por el maestro Macera. Empezaré brevemente por precisar la importancia de Macera en la historiografía peruana. Considerado uno de los más destacados intelectuales peruanos de la generación de 1950, conoció de cerca a los maestros Raúl Porras y Jorge Basadre. Aunque no fue alumno de ellos, supo aprovechar los conocimientos que brindaban a través de amenas tertulias entabladas en la Universidad de San Marcos y en la casa de la calle Colina. Desde esos años, Macera sobresalió por su capacidad de análisis y crítica de la historia peruana. Es además uno de los pocos historiadores sensibles y comprometido con la realidad histórica que le tocó vivir. Poseedor de una conciencia histórica autodefinida como culpable, tuvo gestos de solidaridad con otros actores sociales y populares que no se sentían representados por la historia formal. Su prosa incisiva y provocadora, buscó siempre romper el estado de satisfacción ${ }^{2}$ y promover el espíritu de acción y el juicio crítico y autocrítico. De igual modo, sus reflexiones históricas han sido y serán siempre un modelo de análisis integrador de diversas preocupaciones y perspectivas.

\section{Conociendo al maestro}

Conocí al maestro Pablo Macera en abril de 1985, como alumna de la cátedra Introducción a la Historia. Ese curso, creado en dicho año, no contaba con código de asignatura, pero las autoridades de la Facultad de Ciencias Sociales, recién fundada, dispusieron que fuese dictado para introducir a los ingresantes de la Escuela Académico Profesional de Historia en el quehacer y fundamentos básicos de esta disciplina profesional. Por esos años, los ingresantes de las escuelas profesionales de Antropología, Historia, Sociología y Trabajo Social compartían las clases del curso Introducción a las Ciencias Sociales, dictado por el profesor Roger Iziga. La nueva cátedra a cargo de Pablo Macera fue vista como un privilegio de nuestra promoción, que tendría la oportunidad de escuchar al maestro, que retornaba a las aulas sanmarquinas después de diez años de haberse retirado de la docencia como titular del curso Historia del Perú I, para dedicarse exclusivamente a la investigación. Las clases consistieron en sucesivos seminarios dedicados al análisis y debate de las metodologías empleadas por diversos historiadores. Para ese propósito, el maestro seleccionó varias lecturas, que fueron mecanografiadas en esténcil, impresas a mimeógrafo y agrupadas bajo el título Lecturas Emilio Choy, en homenaje a ese insigne investigador autodidacta. Entre los textos cuya lectura recuerdo puedo mencionar $L a$

\footnotetext{
1 Este testimonio fue escrito en mayo de 2019.

2 Macera, Pablo. (4 de julio de 1975). «Autocritica». Mundial. Revista La Crónica.
}

(C) Los autores. Este artículo es publicado por ISHRA, Revista del Instituto Seminario de Historia Rural Andina de la Facultad de Ciencias Sociales de la Universidad Nacional Mayor de San Marcos. Este es un artículo de acceso abierto, distribuido bajo los términos de la licencia Creative Commons Atribución 4.0 Internacional (CC BY 4.0) [https://creativecommons.org/licenses/by/4.0/deed.es] que permite el uso, distribución y reproducción en cualquier medio, siempre que la obra original sea debidamente citada de su fuente original. 
hipótesis de la caza, de Robert Ardrey, Historia popular, Historia del Pueblo, de Raphael Samuel, y otros ensayos sobre teoría de la Historia, Antropología y Arqueología. Pero la preocupación del maestro no solo estaba puesta en promover la actualización teórica y metodológica de sus alumnos, sino también en prepararlos para las tareas de investigación y uso de fuentes documentales.

Por ese motivo, mi promoción fue invitada a visitar el Seminario de Historia Rural Andina (SHRA). A mediados de 1985, varios condiscípulos estaban apoyando la revisión de documentos y clasificación de datos en el Archivo de la Beneficencia de Lima. En ese entonces, Pablo Macera impulsaba un proyecto sobre la historia de los precios en el Perú. Debo confesar que no participé de este grupo de estudiantes que aceptaron la invitación del maestro, porque otras preocupaciones distrajeron mi atención. Además, el tiempo me resultaba escaso, pues debía asistir a mis cursos de primer ciclo de la carrera de Contabilidad en la Universidad Técnica del Callao, y resolver otros problemas de índole personal.

El regreso de Pablo Macera a la cátedra universitaria coincidió con la publicación de dos libros suyos de Historia para Educación Secundaria por parte de la Editorial Bruño. En ambos libros empleó una metodología didáctica distinta a la tradicional, recurriendo al auxilio de mapas, ilustraciones y cuadernos de trabajo. A su vez, los textos procuraban superar el relato memorístico de fechas y personajes del pasado, pues buscaba hacer de la enseñanza de la Historia un conocimiento crítico del pasado. En la contracarátula de su Historia del Perú 2, dejó escrito:

Aprendamos historia para hacer historia: Una historia mejor que aquella otra que escribimos o leemos. Por eso no nos interesa (autor, profesor, estudiante) saber únicamente nombres y fechas. Lo que necesitamos es comprender los procesos históricos. La historia no es un arte de la Memoria sino una disciplina de la inteligencia y de la evaluación ética ${ }^{3}$.

Estos libros eran vendidos por libreros ambulantes colocados en la puerta de ingreso a la Ciudad Universitaria de San Marcos o en el patio de la Facultad de Letras. El notable esfuerzo del maestro por renovar la pedagogía escolar de la Historia no tuvo compensación económica. Por el contrario, según nos dijo, le produjo gastos irrecuperables, porque extrañamente el Ministerio de Educación realizó cambios de última hora en sus planes curriculares para incorporar temáticas no desarrolladas en sus textos, motivando que estos no fuesen adquiridos para el apoyo de la enseñanza del curso de Historia del Perú en los colegios nacionales.

En julio de 1985, Pablo Macera concluyó el dictado del curso Introducción a la Historia y retomó sus labores de investigación en el SHRA. Sin embargo, volvió a la Facultad de Ciencias Sociales en septiembre de 1986, cuando decidió presentarse como candidato al rectorado de la Universidad. Esta decisión, coordinada con el Frente Democrático Revolucionario y otras fuerzas universitarias de izquierda, no respondió a ningún afán protagónico del maestro. Su postulación sorprendió a muchos, porque dos años antes, en abril de 1984, había declarado en una entrevista concedida a un diario local que «de ningún modo» contemplaba esa posibilidad ${ }^{4}$. La candidatura del maestro fue anunciada en una reunión masiva, celebrada en la antigua aula 1A del pabellón de Letras. Las palabras que dijo esa noche no tuvieron afán proselitista, no arengó, no pidió organizar mítines o marchas a su favor. Su propuesta fue netamente académica e intelectual.

3 Macera, Pablo. (1984). Historia del Perú. 2 La Colonia. Lima: Editorial Wirakipu.

4 Macera, Pablo. (1 de abril de 1984). San Marcos, una universidad que requiere ser fundada. El Caballo Rojo (Suplemento dominical de El Diario de Marka), 4(23). Entrevista de José López Ricci y José Martínez Negrón. 
Propuso a docentes, estudiantes y personal administrativo, fundar una nueva universidad, que superando su crisis de autodefinición y sin perder su «comportamiento reactivo» y contestatario, definiera planes concretos para mejorar la situación del país. Su programa resumido en el eslogan «iDisciplina, democracia y rentas!» no fue comprendido por los grupos aglutinados en la Izquierda Unida, que prefirieron levantar la candidatura del médico Jorge Campos Rey de Castro, quien finalmente fue elegido rector de la UNMSM para el periodo 1987-1989.

Después de esta breve participación en la política universitaria, Pablo Macera se alejó definitivamente de la cátedra. San Marcos perdió la oportunidad de seguir contando con el magisterio de una de las mentes más lúcidas del siglo XX. No obstante, en los años posteriores, docentes y estudiantes acudieron al SHRA para solicitar la publicación de sus trabajos o plantearle consultas referidas al desarrollo de sus investigaciones y tesis. Allí siempre fueron recibidos de manera cordial por el maestro. Por mi parte, no volví a verlo sino hasta 1993, cuando terminé mis estudios universitarios en la Escuela Profesional de Historia.

\section{Su sistema de trabajo y aporte en la recuperación de nuevas fuentes documentales}

En mayo de 1993, visité la oficina del SHRA ubicada en el Colegio Real. Acompañada por Alejandro Salinas, condiscípulo de mi promoción, recorrí los tres patios de este antiguo edificio hasta llegar al ambiente de Dirección, cercano a los talleres de carpintería, que hoy ya no existen. Encontré a Pablo Macera concentrado en sus labores de investigación, sin embargo, al observar nuestra presencia hizo un ademán para que ingresáramos y nos sentáramos frente a su escritorio. Pidió entonces que lo esperásemos un momento. Durante esa espera, observé por primera vez su sistema de trabajo. Él se encontraba revisando y actualizando datos para la reedición de sus textos escolares publicados por Editorial Bruño. Sobre su escritorio, varios libros abiertos mostraban párrafos seleccionados con anotaciones que decían: Xerox 1, Xerox 2, etc. Estos correspondían a citas que como soporte de sus afirmaciones serían insertadas en el texto que venía redactando. De igual modo, en la mesa central de esta oficina, ubicada frente a su escritorio, se entremezclaban fotocopias de lecturas con párrafos resaltados, ilustraciones y hojas mecanografiadas corregidas de puño y letra, en suma, abundante material bibliográfico. Pablo Macera dictaba sus textos, no los escribía. Recuerdo haberle escuchado una vez que su ejercicio de pensar era más rápido que sus torpes manos para escribir a máquina. Dictaba de manera ininterrumpida a sus dos secretarias. Así, mientras la primera terminaba de tomar apunte y se retiraba a mecanografiar, la segunda tomaba la posta para seguir recogiendo el dictado. Cuando el maestro estaba concentrado en su trabajo no se detenía. Su lenguaje literario no se apartaba de los rigores de la heurística y la hermenéutica del historiador. Las secretarias rápidamente escribían a máquina sus anotaciones taquigráficas para que fuesen revisadas por el maestro.

Derrepente, preguntó por uno de sus artículos publicados por la revista Debate. Todos sus colaboradores lo buscaron, pero no lograron encontrarlo. En ese instante, pensé que la espera se estaba prolongando demasiado y corría incluso el peligro de que nos despidiera sin haber sido atendidos. Decidí entonces intervenir y le dije: «Doctor Macera, no se preocupe, yo colecciono esa revista y seguramente tengo en mi casa el artículo que está buscando». De inmediato, me pidió que trajese el artículo y prometió conversar en extenso cuando volviera. Cumplir con lo ofrecido no fue fácil, pues en mi colección de revistas no hallé el número donde se había publicado tal artículo. Tomé entonces la decisión de visitar las oficinas de Editora Apoyo en Miraflores, para comprar el ejemplar. Sin embargo, cuando el personal de apoyo supo que el artículo era requerido por el doctor Macera, me lo facilitó juntos con otros más, también de su autoría. Al día siguiente, regresé con Alejandro Salinas a la oficina del SHRA para entregarle el artículo. El maestro nos recibió con entusiasmo y quiso agradecer el favor invitándonos a trabajar en el SHRA. Desde 
ese instante nos advirtió sobre los escasos recursos de la oficina y la imposibilidad de darnos escritorio y máquina de escribir para nuestro uso. Sin dudarlo, ofrecimos traer nuestras propias máquinas, con la condición que nos permitiera trabajar sin horarios, pues debíamos conseguir ingresos realizando otras labores. Su respuesta fue: ¡Bienvenidos!

Cada semana acudía tres o cuatro días al SHRA llevando en mi mochila una pequeña máquina de escribir Olivetti. Como primera tarea, compartí con Alejandro Salinas, la transcripción paleográfica de documentos en esténciles Gestetner 100, utilizados por el antiguo mimeógrafo manejado por Miguel Pinto. Los documentos transcritos provenían del Archivo Arzobispal de Lima y fueron publicados, acompañados de una presentación, con el título Tierras y Estancias de Chile Colonial (S. XVIII). Este fue el primer y único trabajo realizado en conjunto. Posteriormente, cada uno definió, bajo la dirección del maestro Macera, sus líneas de investigación. A mediados de la década de 1990, el SHRA continuaba abocado a la tarea de publicación de fuentes primarias. Pablo Macera invirtió mucha energía, tiempo y fondos personales para seleccionar, fotocopiar y rescatar documentos de los archivos. Todos quienes formábamos entonces parte del SHRA realizamos dicha labor bajo su dirección.

\section{Tres etapas en el trabajo de investigación en los archivos}

El SHRA desarrolló durante tres décadas una prolífica labor de rescate, edición y publicación de fuentes procedentes de diversos archivos. En mi opinión, pueden distinguirse tres etapas en dicha labor de investigación (1965-1980, 1980-1992 y 1993-2000). Mi presencia en el SHRA estuvo enmarcada en la tercera etapa, que significó para todos los investigadores una transición de la publicación de fuentes, a la elaboración de ensayos e investigaciones especializadas en temas de historia y arte popular, entre otros. Cada una de esas etapas tuvo sus propios objetivos temáticos y equipos de trabajo, pero todas estuvieron enmarcadas dentro de las líneas de investigación trazadas por el maestro Pablo Macera. En ese sentido, mi testimonio puede considerarse una visión retrospectiva interna de la evolución del SHRA como centro de investigación multidisciplinario.

\section{a. Democratizando el conocimiento historiográfico (1965 a 1980)}

Pocos años después de su regreso de Francia, Pablo Macera emprendió el rescate y análisis de fuentes documentales procedentes de la sección Temporalidades del Archivo Nacional del Perú. Apoyado por el grupo de estudiantes fundadores del SHRA, publicó Instrucciones para el manejo de las haciendas jesuitas del Perú (S. XVII - XVIII) en el volumen 2 de la revista Nueva Corónica (1966) (figura 1), editada por el Departamento de Historia de la Facultad de Letras. Este interés por la gran propiedad agraria se enmarcó dentro del convulso ambiente previo a la Reforma Agraria de 1969. Cuando esta se produjo, Pablo Macera, Heraclio Bonilla, Humberto Rodríguez Pastor y Juan Martínez Alier, percibiendo la importancia de esos documentos para co nstruir la historia de la propiedad agraria, sumaron esfuerzos para preservar los archivos de las haciendas expropiadas y contribuyeron a la creación del Centro de Documentación Agraria, cuyo nombre varió después por el de Archivo del Fuero Agrario. De esa manera, toneladas de documentos fueron trasladados y custodiados temporalmente en los ambientes del Colegio Real ${ }^{5}$, mientras se encontraba un local apropiado para su conservación. Esa documentación permitió a los investigadores abordar temas de historia social y económica relacionados con los sistemas de administración de las principales propiedades rurales, la organización del trabajo agrario y las protestas y rebeliones campesinas. 


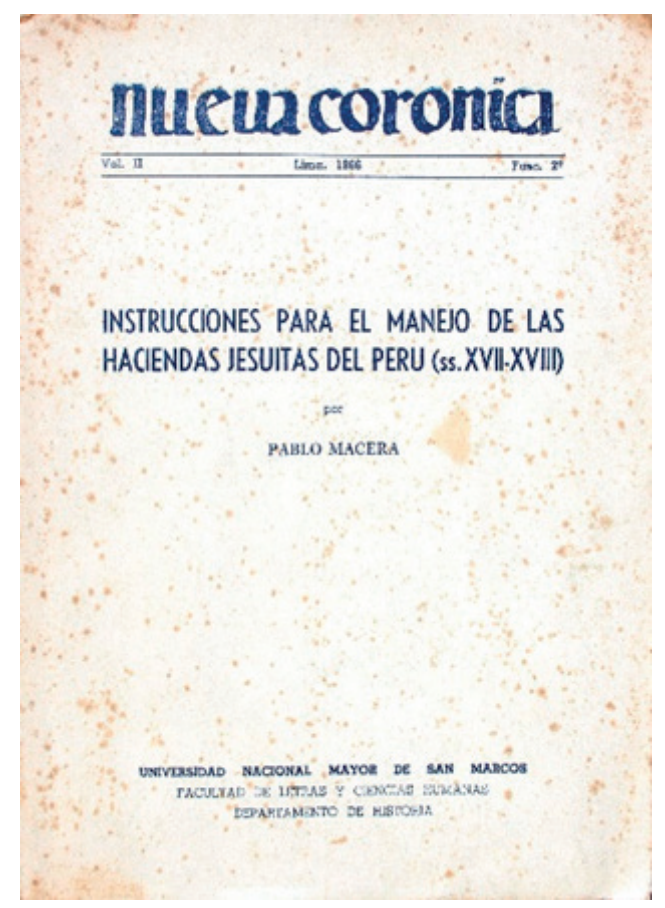

Figura 1. Carátula de la revista Nueva Coronica, la primera publicación fundadora del SHRA. Fotografía: Omar Esquivel.

El proyecto de rescate documental de Pablo Macera comprendía dos niveles: nacional y continental. Se propuso entonces estudiar la composición de las rentas eclesiásticas coloniales, sus cuantías, métodos de recaudación, contabilidad e inversiones. Ningún historiador había revisado aún los fondos de diezmos, expolios, fundaciones y cofradías. Por ese motivo, entre 1974 y 1975, seleccionó y fotocopió documentos sobre diezmos del Arzobispado de Lima. Con ese mismo interés, viajó a Bolivia en 1977 para investigar en archivos bolivianos y recoger datos del Arzobispado de Chuquisaca. Apenas retornó al Perú, emprendió nuevas visitas a los archivos eclesiásticos de Lima, Arequipa y Cuzco. Al mismo tiempo, encargó a Lorenzo Huertas el estudio de las rentas de los obispados de Trujillo y Ayacucho. Estos hechos constatan la trascendencia del proyecto de investigación iniciado, en cuanto a su cobertura geográfica, temática y perspectiva de larga duración en el tiempo. Dificultades de diverso tipo impidieron a Pablo Macera dedicarse al análisis de todas las fuentes recopiladas ${ }^{6}$. No obstante, la edición/publicación de las fuentes sobre diezmos coloniales reveló la importancia que estos tenían para la definición de indicadores sociales por parte de la historiografía andina ${ }^{7}$. Por entonces, el maestro estaba comprometido con su labor de abrir caminos para que sus alumnos emprendieran sus propias investigaciones. Esto motivó la búsqueda de fuentes documentales relacionadas con nuestra historia republicana (siglos XIX y XX). Revisó entonces numerosos expedientes de matrículas de contribuyentes, padrones de tributos, informes de prefectos y autoridades fiscales de los archivos históricos de los ministerios de Hacienda, Fomento y Trabajo, para reconstruir el mapa socio-económico del Perú republicano.

Durante esta etapa, Pablo Macera consideró prioritaria la difusión de las fuentes documentales mediante trabajos precedidos por un breve estudio introductorio. Dentro de ese propósito, el SHRA no tuvo la intención de convertirse en lo que hoy podría denominarse un think thank de las ciencias sociales. Sus metas consistían en publicar resultados iniciales de investigaciones en curso y sobre todo, compartir la información con la comunidad de historiadores y otros 
científicos sociales. Adoptado ese estilo de trabajo, el maestro advirtió que proporcionando materiales básicos:

nos arriesgamos a que nuestras conclusiones sean criticadas; y nuestras investigaciones dejan de ser propiedad personal y escondrijo psicológico para circular entre todos como bien común. Pero esto es precisamente lo que necesita con urgencia la historiografía peruana. Constituye también el único modo de evitar una sobre-identificación de cada uno de nosotros con nuestro trabajo y hacer posible una mayor libertad para apreciar nuestras limitaciones. ${ }^{8}$

\section{b. Rompiendo el miedo al uso de la estadística en la Historia (1980 a 1992)}

Durante su estancia en Francia, a inicios del decenio de 1960, Pablo Macera descubrió la importancia de las estadísticas históricas para el estudio del desarrollo socio-económico de las naciones. Las magistrales disertaciones sobre precios que escuchó de Fernand Braudel y Pierre Vilar, y la lectura de los libros de Francois Simiand, Ernest Labrousse, y sobre todo del extraordinario trabajo de Gastón Imbert titulado Des Mouvements de Lougue durée Kondratieff, fueron decisivos para analizar la relación entre los trend seculares (tendencias) y los movimientos Kondratieff para comprender la necesidad de construir series cuantitativas de la producción y precios. Pablo Macera inició en 1963, la recopilación de información cuantitativa con el propósito de elaborar estadísticas históricas coloniales y republicanas. Sin embargo, esa tarea recién tomó impulso en la década de 1980, cuando jóvenes historiadores se vincularon con el proyecto sobre la historia de los precios en el Perú. Ellos, bajo la dirección de Macera, revisaron fuentes antes trabajadas y rompieron, como recuerda el maestro, el miedo al empleo de programas de informática en la sistematización de los datos estadísticos. Auxiliados por la tecnología, realizaron nuevos ordenamientos, agruparon los precios por circunscripciones (ciudades, haciendas) y en relación con los distintos tipos de medida, valor y medios de pago.

Para esta investigación cuantitativa, el maestro organizó un nuevo equipo de historiadores encargados de registrar la información consultada en el Archivo de la Beneficencia Pública de Lima y los archivos de los conventos San Francisco, Santa Clara y Buena Muerte. También fueron revisados algunos fondos específicos del Archivo General de la Nación. En el curso de este proyecto, Pablo Macera observó la alarma surgida por la evolución de los precios durante la crisis de 1929, y la conformación del Comité Internacional para la Historia de los Precios. En cierta medida, esa crisis hizo posible el desarrollo del conocimiento sobre las series de precios históricos, pues este podía contribuir a prevenir nuevas coyunturas inflacionarias. Sin embargo, el Comité no incluyó dentro de sus programas la historia de los precios coloniales. El maestro quiso llenar ese vacío planteándose las siguientes interrogantes: ¿Hubo o no sectores $\mathrm{y}$ tendencias en el curso general de los precios coloniales que dependieron en mayor medida de factores internos antes que externos? ¿No sería posible que el curso de algunos precios coloniales hubiese anticipado lo que más tarde ocurriría en las metrópolis $?^{9}$ Este proyecto dejó abierta muchas sendas para la investigación, pero concluyó en 1992 con la publicación de tres volúmenes titulados Los Precios del Perú. Siglo XVI- XIX. Fuentes, publicados por el Banco Central de Reserva.

En el Apéndice del estudio introductorio del primer volumen, Pablo Macera propuso métodos de trabajo para procesar la información recopilada. Definió de esa forma un modelo organizativo consistente en cinco tablas tituladas: Hoja de trabajo N. 1 (registro de información en general),

8 Macera, Pablo. (1972). Tierra y Población en el Perú (SS. XVIII - XIX), tomo 1. Lima: Seminario de Historia Rural Andina.

9 Macera, Pablo. (1994). Los Precios del Perú. Siglos XVI - XIX. Fuentes, tomo I. Lima: Fondo Editorial del Banco Central de Reserva del Perú. 
Hoja de trabajo N. ${ }^{\circ} 2$ (registro de precios por meses), Hoja de trabajo N. ${ }^{\circ} 3$ (registro de precios por estaciones), Hoja de trabajo N. ${ }^{\circ}$ (registro de precios en distintos años) y Hoja de trabajo N. 5 (registro del promedio anual de precios). Hizo además sugerencias sobre la forma cómo debía buscarse la información sobre los precios en los archivos de Lima o del interior del país. El maestro compartió su experiencia de trabajo porque quería distinguirse de otros historiadores quienes, en un exceso de celo, omitían dar detalles sobre sus proyectos de investigación como si fueran el «Santo Grial».10

\section{c. Trabajando con nuevas fuentes (1993 al 2000)}

Durante 1993, Pablo Macera dedicó varios meses a la recopilación, edición y publicación de fuentes documentales del Archivo Arzobispal de Lima. En simultáneo, seguían publicándose documentos reunidos en el decenio de 1980. No obstante, el maestro venía preparando nuevos proyectos de investigación que lo condujeron a revisar materiales procedentes de la Hemeroteca del Banco Central de Reserva. Tuve entonces la oportunidad de trabajar desde 1995 hasta 1999 con Alejandro Salinas en la revisión de los diarios El Comercio (1839-1899) y El Peruano (18261899), para elaborar una base de datos con las noticias y artículos publicados sobre sociedad y economía durante el siglo XIX. Culminado el proceso de selección, se procedió a microfilmar más de 4000 artículos utilizados en la preparación de dos conjuntos documentales titulados Economía del Perú Siglo XIX (Información/análisis/El Peruano) y Pensamiento Económico y Social del Perú: 1859-1879/El Comercio. Posteriormente, parte de esa base de datos ha sido utilizada por Salinas y mi persona en trabajos publicados en el SHRA desde el año 2001.

A partir de 1999, participé en la exploración de fondos pertenecientes a las cámaras de senadores y diputados del Congreso de la República. Con este proyecto, el maestro quiso evaluar las implicancias sociales y políticas de la obra legislativa durante el siglo XIX. La publicación del material seleccionado dio origen a ocho volúmenes titulados Parlamento y Sociedad en el Perú. Bases documentales Siglo XIX. Selección y estudio preliminar de Pablo Macera. Los dictámenes, proyectos de ley e informes debatidos en el parlamento e incluidos en esa obra permitían «acceder a una sociología de la acción legislativa, una sociología en la que aparecen los orígenes, las causas y los fundamentos de tipo económico, social y territorial que condicionaban las acciones públicas y privadas desde dentro o fuera del Parlamento». ${ }^{11}$

El año 2000 marcó el término de la dirección del SHRA ejercida por Pablo Macera desde su fundación. Desde el 2001 el maestro jubilado continuó laborando ad honorem en el SHRA, pero en calidad de Director Fundador. Fue precisamente en dicho año cuando fuimos convocados Alejandro Salinas, Santiago Tácunan y mi persona para participar en un proyecto sobre la historia de los ferrocarriles. Recibimos entonces el encargo de revisar los antiguos archivos de la Peruvian Corporation conservados por la Empresa Nacional de Ferrocarriles del Perú (ENAFER) en liquidación. El maestro había recibido aviso de que esos archivos estaban depositados en los almacenes de la empresa Industrias Militares del Perú (INDUMIL Perú). En esta oportunidad, transcurrido un año de clasificación y estudio de los documentos, en colaboración con Alejandro Salinas, fueron preparados dos volúmenes sobre la historia ferroviaria peruana entre 1821 y 1899 , que aún permanecen inéditos.

\section{Pablo Macera y sus aportes al estudio del arte popular y la tradición oral amazónica}

10 Macera, Pablo. (1994). Los Precios del Perú. Siglos XVI - XIX. Fuentes, tomo I. Lima: Fondo Editorial del Banco Central de Reserva del Perú.

11 Ver el Estudio preliminar en: Macera, Pablo. (1998). Parlamento y Sociedad en el Perú. Bases Documentales Siglo XIX, tomo 1. Lima: Ediciones del Congreso del Perú. 
En el SHRA, no solo encontré espacios para desarrollar mi vocación como historiadora, sino que también fui partícipe de investigaciones sobre arte popular amazónico. A mediados de 1996, recibí la invitación del maestro para coordinar el rescate y puesta en valor del arte y tradición oral amazónicos. Además, me sugirió evaluar la pertinencia de aplicar los métodos y técnicas empleados por él en sus estudios de la tradición cultural andina. La lectura de sus estudios sobre pintura mural y pintores populares andinos me permitieron comprender la importancia de la renovación conceptual y metodológica contenida en el enfoque social que le daba al estudio del arte. Similar atención puse en sus ideas sobre la permanencia de la tradición artística andina, a partir del redescubrimiento de la obra de Tadeo Escalante y de los vínculos que esta tenía con las prácticas de los llamados «primitivos» pintores cusqueños coloniales. Por lo tanto, resultaba crucial precisar cuándo un descubrimiento tenía en realidad la condición de redescubrimiento. Asimismo, tomé nota de sus agudos juicios sobre la representación de personajes históricos en las pinturas populares, como aquella de la victoria de Sangarará (1780), pintada sobre un cuero, en cuyo centro aparece Tupac Amaru II. Esta imagen del revolucionario líder revelaba la vitalidad de su epopeya en la memoria andina, a pesar de haberse proscrito todo vestigio grafico del personaje por parte de las autoridades coloniales.

Otro aspecto importante contenido en sus estudios estaba referido a la forma en que las prácticas artesanales servían como vehículos para transmitir las tradiciones de generación en generación. En ese contexto, destacó el papel cumplido por Joaquín López Antay en la continuidad de la confección y uso del cajón San Marcos, rebautizado como retablo, cuya difusión había sido favorecida por los circuitos de arrieraje y el ciclo de la vida rural en la región ayacuchana. Ciertamente, todas estas ideas me daban el marco de referencia para efectuar una adecuada valoración del arte popular desde una perspectiva social. Sin embargo, aún debía aprender a escuchar y registrar las memorias de estos creadores de tradiciones. El libro sobre Jesús Urbano Rojas, publicado bajo el título de Santero y Caminante / Santoruraj Nampurej (1992), ofrecía una experiencia maravillosa de cómo un investigador convertido en «jalador de lengua», facilita la evocación de recuerdos por parte del artista dialogante. Constituyó un auténtico reto conjugar todas estas metodologías dentro de una visión intercultural centrada en el estudio del arte popular amazónico. Por lo demás, Pablo Macera juzgaba imprescindible percibir el deterioro de la función socializadora del arte popular, producida cuando este dejaba el entorno rural para insertarse en la vida urbana. Esta situación había sido advertida por el maestro en 1974 cuando indicó que: «En países culturalmente invadidos como el Perú urge por esta razón introducir el arte como una experiencia cotidiana y democratizada. Todo arte desde luego, pero sobre aquel que además de su propio valor (razón primera) sea también un arte testigo de nuestra vida social». ${ }^{12}$

Esos fueron los principios que animaron el surgimiento del taller de trabajo intercultural andino-amazónico del SHRA. Esta experiencia coincidió con las primeras migraciones de los nativos amazónicos a la capital. Aún no se habían formado los asentamientos shipibo de Cantagallo y asháninka de Huaycán. Los migrantes shipibos evitaban hablar su lengua originaria y buscaban espacios dentro de la cultura mestiza urbana. El proceso de adaptación no fue similar en hombres y mujeres. Los primeros perdían con mayor rapidez el apego a sus tradiciones, mientras las segundas, mediante el uso de sus vestidos tradicionales y la venta de collares y pulseras, defendían su identidad. En medio de este escenario, el SHRA recibió en 1997 la visita del artista Víctor Churay Roque, poblador bora nacido en la comunidad de Pucaurquillo (Loreto). Él había ganado un año antes el I Concurso de arte nativo sobre corteza de llanchama. Su propuesta artística impresionó a Pablo Macera, que estaba convencido del potencial de Churay para convertirse en el

12 Ver el artículo: «Tadeo Escalante y los murales de Acomayo», en: Macera, Pablo. (2009). Trincheras y Fronteras. Del Arte Popular Peruano. Lima: Fondo Editorial del Congreso del Perú. 
Guaman Poma de la Amazonia. Aunque era bilingüe (bora/español), tenía pocos conocimientos sobre la historia y tradiciones de su pueblo. Los contenidos de su memoria estaban construidos a partir de los hechos y personajes aprendidos en la escuela. Ante esa situación, Pablo Macera sugirió a Víctor dialogar con la gente de su comunidad para que, utilizando su maravilloso arte pictórico, nos revelara su cosmovisión, tradiciones orales y costumbres sociales y festivas. En el SHRA, Churay tendría los elementos materiales para desarrollar su propuesta y obtener el reconocimiento que le era negado por quienes la calificaban de simple expresión artesanal. El maestro confiaba en que Churay finalmente lograría impulsar la aparición de una generación de pintores amazónicos comprometidos con la defensa de sus tradiciones, aunque tuviesen que batallar contra los mismos prejuicios que en 1976 trataron de minimizar la dimensión cultural de la obra artística de Joaquín Lopez Antay.

De acuerdo con ese propósito, Pablo Macera y mi persona cumplimos la labor de gestores culturales para abrir espacios donde Churay pudiera exhibir sus obras. Asumí además las tareas de investigación y curaduría para la organización de las exposiciones. Las primeras de estas, realizadas en las salas de exposiciones del BCRP (1998) y Museo de la Cultura Peruana (1999), mostraron las primeras llanchamas ilustradas con elementos de su cosmovisión. Con la intención de apoyar el trabajo iniciado por Churay, Pablo Macera me encargó coordinar la visita a Lima del padre de Churay, su tía Julia Mibeco y Eduardo Soria, para que entre todos recordaran sus historias, mitos y leyendas. Como resultado de esas conversaciones, Churay pintó, desde la perspectiva bora, las primeras escenas de la explotación sufrida por su pueblo durante la época del caucho. También pintó escenas de sus fiestas rituales, sesiones curanderiles de sus taabóóbé y los personajes míticos habitantes de la tierra, cielo y aguas. Al respecto, en coautoría con Víctor Churay, se organizó la información referida a las tradiciones festivas y fue publicada por el SHRA bajo el título Fiestas tradicionales de los bora (2001). Desde ese momento, Churay adquirió la condición de representante cultural de su pueblo, privilegio que se sumaba a su condición de sucesor de la jefatura del clan pelejo, ostentada entonces por su padre.

Durante casi dos años, Churay había perfilado su propuesta artística en los talleres del SHRA y los acogedores ambientes del Colegio Real. De allí salió en búsqueda de nuevos escenarios para continuar con su labor artística, interrumpida por su trágico fallecimiento el año 2002. El vacío dejado por Churay fue llenado por otros pintores con los que trabajábamos en forma paralela e ininterrumpida. Por ejemplo, Roldán Pinedo y Elena Valera practicaban el «arte de a dos», pues ambos pintaban el mismo cuadro. Ellos emplearon pigmentos naturales para pintar animales y plantas del Ucayali sobre telas de tocuyo teñidas con caoba. Por su parte, Herminio Vásquez y Robert Rengifo (Chonomeni), narrador y pintor shipibos, respectivamente, produjeron varios cuentos ilustrados (1999), que reflejaron la compleja relación entre oralidad y escritura, estudiada por María Chavarría bajo el concepto de «literacidad $»^{13}$. Ellos dieron impulso al nuevo proyecto pintura/palabra de Pablo Macera, cuyo objetivo consistía en publicar relatos y pinturas de artistas amazónicos bajo el formato de cuentos para uso de las escuelas interculturales. Por su parte, los relatos y dibujos de Lastenia Canayo (Pecon Quena) revelaron la existencia de los Ibos, espíritus dueños de plantas y animales, que regulan los códigos de conducta entre hombre y naturaleza, y castigan a los trasgresores. A su vez, Enrique Casanto escribió una historia ilustrada de Juan Santos Atahualpa, su hijo Josecito y los guerreros asháninkas aliados, personajes rodeados de atributos mesiánicos semejantes a los del Inkarri. En el artículo «La amazonia en el quehacer del Seminario de Historia Rural Andina», publicado en el n. ${ }^{\circ}$ de la Revista ISHRA (2016), hago un

13 Ver el trabajo de María Chavarría: «De la oralidad a la literacidad: aproximaciones recientes en la Amazonía», en Chaumeil, JeanPierre; Espinoza, Oscar y Chaparro, Manuel (Eds). (2011). Por donde hay soplo. Lima: IFEA-PUCP-CAAAP. 
balance de la contribución de Pablo Macera y el SHRA al conocimiento de esta generación de narradores/pintores amazónicos.

La colección Cuentos Pintados del Perú, creada por Pablo Macera en 1995, me permitió participar activamente en un proyecto intercultural, cuyo protagonismo estuvo puesto en los narradores/pintores andinos y amazónicos. En búsqueda de apoyo se hicieron gestiones ante el Ministerio de Educación, pero no hubo resultados positivos. Por el contrario, la empresa privada puso mayor interés en el proyecto. Fue así como Pablo Macera logró que Fundación Inca Kola financiara la impresión y difusión de los Cuentos Pintados preparados en los talleres del SHRA. La publicación de textos con relatos bilingües (lengua originaria/español), acompañados de dibujos, tuvo tres objetivos: 1. Reforzar la identidad cultural de los niños amazónicos, 2. Facilitar el conocimiento de las culturas nativas entre los escolares hispano hablantes de otras regiones, y 3. Ofrecer materiales etnográficos para el análisis de los especialistas (antropólogos, historiadores y linguistas), tanto como presentar materiales informativos para turistas extranjeros y nacionales. En ese trabajo se respetaron las reglas de normatización de las lenguas amazónicas aprobadas por el Ministerio de Educación, que además estaban en proceso de actualización y cambio, a diferencia de las lenguas andinas, cuyos alfabetos y gramáticas no presentaban esta particularidad.

Tuve entonces el privilegio de intercambiar ideas con el maestro sobre el método más adecuado para rescatar la tradición oral amazónica, que estaba perdiendo vitalidad como mecanismo de trasmisión de conocimientos. Coincidimos en que se hallaba en una situación más vulnerable respecto de las memorias quechua y aymara, pues observamos olvidos y una especie de tiempos vacíos en sus relatos, más aún cuando existían muy pocos registros audiovisuales de sus tradiciones culturales. Pablo Macera consideraba a la memoria colectiva un tesoro que debía resguardarse, porque equivalía a las bibliotecas de las culturas letradas. Sin embargo, descubrimos también que las culturas amazónicas, recogiendo una tradición prehispánica, poseían otros elementos culturales para conservar y evocar sus recuerdos. La memoria de los pueblos nativos no dependía necesariamente de los relatos, porque podía activarse mediante representaciones simbólicas o imágenes semióticas plasmadas en pinturas faciales y corporales, diseños en cerámica, marcas de caza, etc. Por ese motivo, el maestro me expresó su preocupación sobre cuánto de esa tradición visual se perdería con la aplicación de una política educativa basada exclusivamente en la alfabetización. Estas reflexiones despertaron mi interés por el estudio de esas representaciones y el papel que cumplían entre los pueblos shipibo y asháninka, publicando en el SHRA cuatro trabajos titulados Arte y cultura del monte. Asháninca del Perené (2002), Introducción al mundo semiótico de los diseños shipibo-conibo (2004), Demonios del monte. Idea del mal en la cosmovisión amazónica (2005), y El discurso de las Imágenes. Simbolismo y nemotecnia en las culturas amazónicas (2009). (Figura 2)

De esa forma, Pablo Macera nos enseñó a trabajar con las fuentes orales, con la misma dedicación y rigurosidad con que analizábamos las fuentes documentales. Ambas resultaban necesarias para renovar la teoría y metodología de las ciencias sociales. El maestro puso énfasis en la urgencia de acabar con aquel prejuicio que consideraba a los pueblos carentes de escritura alfabética como sociedades sin historia o «pueblos ahistóricos». Aquel prejuicio al que se aferraban los historiadores tradicionalistas no tenía sentido alguno, porque historia y escritura no debían considerarse aspectos inseparables. En ese sentido, Pablo Macera afirmó: «Pienso que la realidad histórica es comprendida por la mayoría del país, desde las clases populares hasta las dominantes y privilegiadas, a través de otros circuitos que no son los de la investigación académica». Por lo demás, las clases populares han creado diversos circuitos y manifestaciones artísticas para expresar sus penas y alegrías, sus esperanzas y reclamos, con una creatividad desbordante. 


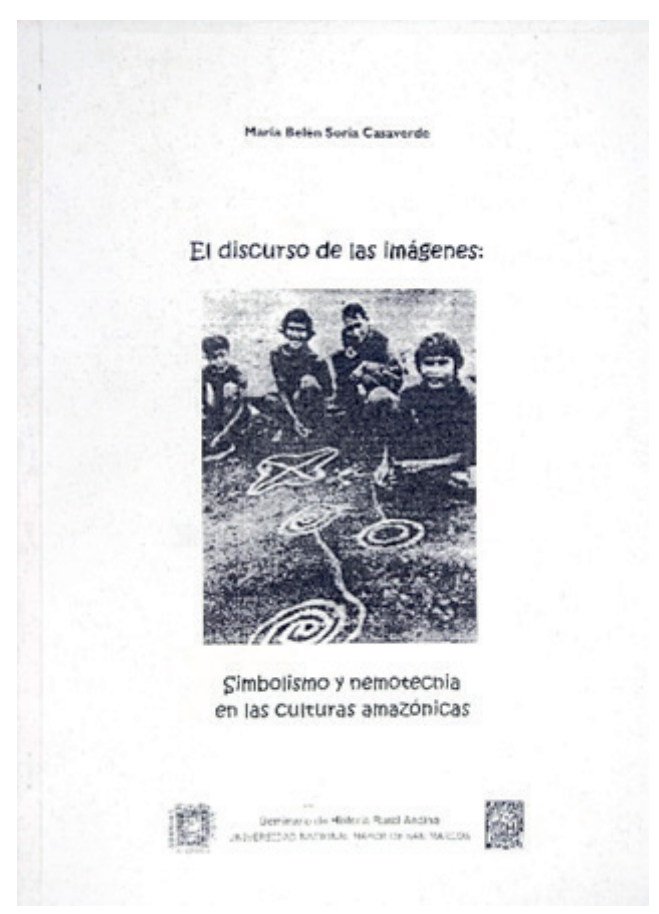

Figura 2. Carátula del libro El discurso de las imágenes. Fotografía: Omar Esquivel.

Ciertamente, Pablo Macera promovió el rescate del arte y tradición oral amazónicos, como en su momento lo hicieron José María Arguedas, Arturo Jiménez Borja, Alicia y Celia Bustamante y Elvira Luza, quienes difundieron en la capital la literatura y artes de los pueblos andinos. En 1999, el maestro entregó en fideicomiso al BCRP una parte de su colección de arte popular andino y amazónico. En aquella ocasión participé en la catalogación de diversas piezas artísticas, que fueron exhibidas en el segundo piso de la Casa de la Moneda. Posteriormente dicha colección fue trasladada al Museo del BCRP ubicado en la esquina de los jirones Lampa y Ucayali. No obstante, todavía conserva una vasta colección de arte andino y amazónico en su casa, la cual tuve oportunidad de estudiar durante los años que trabajé en el Seminario. En suma, aprender Historia con el maestro Pablo Macera fue una experiencia profesional invalorable, la cual guardaré siempre en mis recuerdos con infinito agradecimiento. La mejor enseñanza recibida de Pablo Macera fue el compromiso que como historiadores tenemos de aplicar metodologías interdisciplinarias para democratizar la investigación y valorar la importancia de los pueblos en el proceso histórico.

\section{María Belén Soria Casaverde}

belamazo@gmail.com

Universidad Nacional Mayor de San Marcos

Publicado online: 27/12/2021 